\title{
The Learning Faculty: Characteristics of Graduates
}

\section{James L. Heap}

A journal titled Teaching $\mathcal{E}$ Learning is perfectly situated, by title and audience, as a place for reflections on the wide-ranging impact of a focus on learning within a Faculty of Education. As the new dean, I want to share ideas about learning that excite and animate us daily to become The Learning Faculty. In particular, I want to tell you what we are doing at the Faculty of Education to identify the characteristics of graduates that we most value. We need your ideas, as administrators and teachers, about the characteristics that teachers will need in the coming decades so that we, collectively, can ensure that graduates of Brock University pre-service and in-service degree programs are prepared to serve the needs of Ontario.

\section{The Shift to a Focus on \\ Learning}

There has been a shift in educational theory and practice in the last half century, from behaviourism to constructionism. Educational theorists, researchers and practitioners since Piaget and Vygotsky have focused on learning as a constructivist process, rather than as a responsive or adaptive process. The tenets of constructionism expounded by psychologists converge at many points with the assumptions of social constructivism that have found expression since the 1960s in the theoretical and empirical work of social scientists, including educational researchers.

We need to redefine
excellence in instruction,
focusing on learning.

The irony is that while the Academy has been the source of knowledge about constructivism, the actual practice in the Academy, i.e., instruction, has been slow to reflect the principles of constructivism. We have depended across the university on the lecture method, as if our job is to pour knowledge into empty vessels. Over the past ten years, though, there has been an increasing dialogue in post-secondary education around what it means to take seriously the idea that people construct knowledge. This is leading to a shift of focus in instruction in post-secondary education, from teaching to learning.

The shift in focus, and what it means, was articulated most strikingly by Robert B. Barr and John Tagg (1995) in an influential article in Change magazine. They wrote about a shift from a focus on teaching to a focus on learning where faculty are designers of powerful learning environments; where curriculum design is based on an analysis of what a student needs to know to function in a complex world rather than on what the teacher knows how to teach; where an institution is judged, not on the quality of the entering class, but on the quality of aggregate learning growth possessed by its graduates; where compartmentalized departments are complemented by crossdisciplinary cooperatives; where every employee has a role to play and a contribution to make in maintaining a learner-centred environment; and where the institution itself is a learner-a learning organization.

This shift is well under way in faculties of education, particularly in the way that instruction is delivered. Faculties of education lead the way within universities in focusing on learning, but there is still much to do, to explore, and to learn. We need to redefine excellence in instruction, focusing on learning.

\section{Redefining Excellence: Focusing on Learning}

If we are to focus on learning we need to focus on the kind of "outcomes" we wish to produce. I say "outcomes" because rather than the sort of micro-behaviours often associated with outcomes rhetoric, I mean to denote something more general and valuable. By outcomes I mean the characteristics of graduates of our undergraduate and graduate programs that we seek to foster through coursework, practica, internships, projects and theses. A statement of these characteristics should focus on central skills, talents, abilities, values, commitments and beliefs that our graduates should have, based upon professional standards of excellence and expectations for citizens who have a formative role in society. The statement of these characteristics 
should be general enough to capture important learning but clear and specific enough to be measurable. The statement should focus on characteristics that will develop and endure but that can be assessed in some form now.

The characteristics we wish our graduates to have must form the basis for developing future curricula. They must provide direction, as the desired ends, for all instructional activity. They will inform potential students and potential employers about the intentions of the faculty. They will form the basis for assessment.

What should be the defining characteristics of graduates of Faculty of Education programs at Brock University?

There are two ways of answering this question. One can be called internal, the other external. The internal answer is the one generated by the faculty themselves. The external answer represents the views of the stakeholders who have an interest in the nature and quality of our graduates.

The external stakeholders include the residents of Ontario, who all benefit, however indirectly, from the quality of Ontario's teachers. Politicians, policy makers, policy advisors, educational agencies and accrediting bodies have an important stake in ensuring that the characteristics of graduates of preservice and in-service programs in the province well serve the emerging educational needs, backgrounds and circumstances of Ontario's current and future school-age children.

The stakeholders with the most pressing interest in the character- istics and quality of Brock graduates in education, though, are the employers and professional colleagues of our graduates. These are our school-based stakeholders: school boards, directors, superintendents, principals, consultants and all members of the teaching profession, particularly as represented by teacher federations.

\section{The Internal Plan}

In order to generate an internal answer to the question of the characteristics that should define a graduate of the Faculty of Education the members of the faculty are convening a full-day Faculty Forum in October. The Forum is designed to focus attention on the distinctive qualities of graduates that we desire our students to develop, no matter in what program they are enrolled. The Forum will provide an opportunity for us as faculty to discover the commitments we share to add value for our students and their employers, and for the local, regional, national and global communities that they and we serve.

The October Faculty Forum, actually, is even more ambitious. We aim to formulate the impact that we seek to achieve not only through our instructional efforts, but also through our scholarship and institutional, community and professional service. Specifying the intended impact of our instructional, scholarly and service efforts is part of the plan to clarify our identity as The Learning Faculty at Brock University.

\section{The External Plan}

This short note is part of the very plan on which it reports. In sharing with you, the reader, discussion of the shift to a focus on learning, and detailing elements and aspects of the learning outcomes we call "characteristics of our graduates," I am inviting you to share your views and expectations about the needed characteristics of current and future teachers in Ontario. As part of the readership of Teaching \& Learning you are well positioned to offer informed opinions about what current and future teachers and administrators should know, be able to do, and be committed to.

To carry out this first step in our "external plan," please reread the "Redefining Excellence" section above. Reflect on your professional and research-based knowledge, your personal experience, your beliefs and commitments regarding education, and your understanding of our kind of multi-cultural society as it continues to evolve in a global context. What should be the characteristics of graduates of education programs? What characteristics of our graduates will most appropriately and effectively serve the needs of our society and its school-aged children in the next five to fifteen years?

Please share your reflections with me via email at jheap@brocku.ca. Your response will become part of the external answer to the question of what characteristics Brock Faculty of Education graduates should have, and should be supported in attaining. The pool of responses will provide material for further discussion with stakeholders, and input from them. What is learned from stakeholders will be shared with colleagues at the Faculty of Education, and in other Faculties at 
Brock. My colleagues and I are particularly interested in where and how the internal and external answers to the characteristics question overlap, or diverge. The faculty who compose the Faculty of Education have the ultimate responsibility to identify the characteristics that our programs should foster. They, and I, need your views, though, because the characteristics of our graduates will impact the characteristics of teachers and administrators in Ontario, especially in the Golden Horseshoe, where the primary readership of this journal is to be found. Thank you, in advance, for your helpful response.

\section{References:}

Barr, R. B., \& Tagg, J. (1995). From teaching to learning: A new paradigm for undergraduate education. Change, 27, 13-24. Retrieved September 28, 2005 from http://critical.tamucc.edu/ rblalock/readings/tch2learn.htm]

James L. Heap, Ph.D. is Dean of the Faculty of Education at Brock University. He has joined Brock from Ohio University, where he served from 1998 to 2005 as Dean of the College of Education. Before moving to Ohio he taught for many years at OISE, where he was Chair of the Department of Sociology in Education, and founding Chair of the Department of Theory and
Policy Studies when OISE merged with the Faculty of Education at the University of Toronto in 1996. His scholarly interests include the social

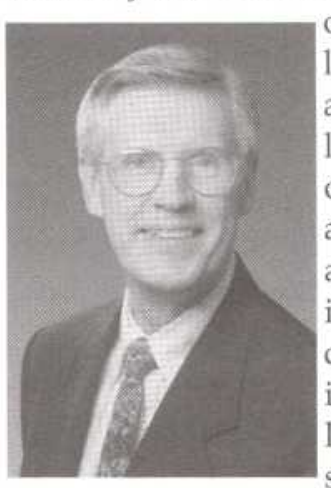
organization of li t e r a c y activities, l e a $r \mathrm{n}$ i $\mathrm{g}$ organizations, and qualitative approaches to inquiry. He is c urrent $1 \mathrm{y}$ involved in a longitudinal study of the practices of high and low valueadded teachers of language arts and mathematics at the Primary and Junior Levels.

\section{Hurry! \\ Courses are filling up fast. \\ For Registration information:} www.brocku.ca/registrar/guides/inservice

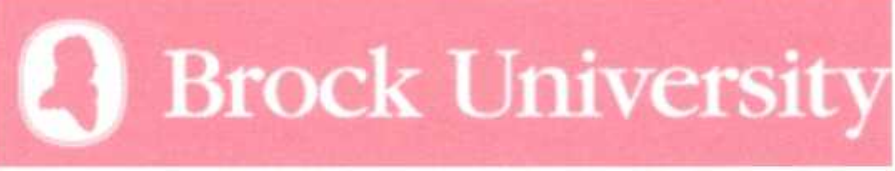

Winter Starts:

Duration 5: January 03, 2006 - March 17, 2006

\section{ONLINE}

Additional Qualification Courses

www.brocku.ca/registrar/guides/inservice

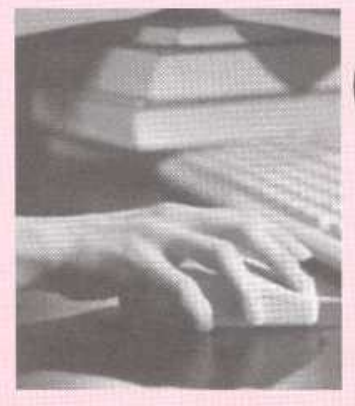

\section{CENTRE FOR CONTINUING TEACHER EDUCATION} Faculty of Education
Centre for Continuing Teacher

Education

Faculty of Education

500 Glenridge Ave.

Welch Hall

St. Catharines, ON

Phone: $\quad 905.688 .5550 . \times 3342$

Fax: 905.641 .5265

Email: aqaded@brocku.ca

marie@brocku.ca
Code

EDUC 9F29

EDUC 9F26

EDUC 9F66

EDUC 9 F69

EDUC 9F77

EDUC 0F99
Course

Librarianship Pt 3

D \& T Pt 3

Guidance Pt 3

ESL Pt 3

Junior Basic

Special Ed Pt 3
D

05

05

05

05

05

05
Start Date

01 January 3

01 January 3

01 January 3

01 January 3

01 January 3

01 January 3

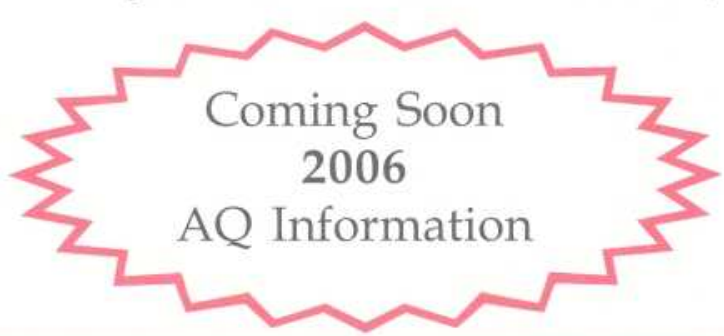

